\title{
Genetic changes of survival traits over the past 25 yr in Dutch dairy cattle
}

\author{
M. L. van Pelt, ${ }^{*} \dagger^{1}$ V. Ducrocq, $\ddagger$ G. de Jong, ${ }^{*}$ M. P. L. Calus, $\dagger$ and R. F. Veerkamp $\dagger$ \\ ${ }^{*} \mathrm{CRV}$ BV, Animal Evaluation Unit, PO Box 454, 6800 AL Arnhem, the Netherlands \\ †Animal Breeding and Genomics Centre, Wageningen UR Livestock Research, PO Box 338, 6700 AH Wageningen, the Netherlands \\ ‡GABI INRA, AgroParisTech, Université Paris-Saclay 78350 Jouy-en-Josas, France
}

\begin{abstract}
Genetic correlations and heritabilities for survival were investigated over a period of 25 yr to evaluate if survival in first lactation has become a different trait and if this is affected by adjusting for production level. Survival after first calving until 12 mo after calving (surv_12mo) and survival of first lactation (surv_1st_ lac) were analyzed in Dutch black-and-white cows. The data set contained 1,108,745 animals for surv_12mo and 1,062,276 animals for surv_1st_lac, with first calving between 1989 and 2013. The trait survival as recorded over 25 yr was split in five 5-yr intervals to enable a multitrait analysis. Bivariate models using subsets of the full data set and multitrait and autoregressive models using the full data set were used. Survival and functional survival were analyzed. Functional survival was defined as survival adjusted for within-herd production level for 305-d yield of combined kilograms of fat and protein. Mean survival increased over time, whereas genetic variances and heritability decreased. Bivariate models yielded large standard errors on genetic correlations due to poor connectedness between the extreme 5 -yr intervals. The more parsimonious models using the full data set gave nonunity genetic correlations. Genetic correlations for survival were below 0.90 between intervals separated by 1 or more 5 -yr intervals. Genetic correlations for functional survival did not indicate that definition of survival changed $(\geq 0.90)$. The difference in genetic correlations between survival and functional survival is likely explained by lower emphasis of dairy farmers on culling in first lactation for low yield in more recent years. This suggests that genetic evaluation for longevity using historical data should analyze functional survival rather than survival.
\end{abstract}

Key words: longevity, survival, genetic correlation

Received April 1, 2016.

Accepted August 16, 2016.

${ }^{1}$ Corresponding author: mathijs.vanpelt@wur.nl

\section{INTRODUCTION}

Longevity, also known as survival, is an important trait for dairy farmers because it is related to economic and animal welfare reasons. In the Netherlands, pressure exists from society to increase the longevity of dairy cows (LTO, 2011). The longevity of a dairy cow is determined by the culling decision of the farmer, and farmers decide to cull dairy cows for various reasons such as mastitis, fertility problems, lameness, or low production (Beaudeau et al., 2000; Zijlstra et al., 2013). These culling reasons are likely to be affected over years by changes; for example, in national regulation and legislation (e.g., quota system), feed costs, milk price, and revenues for culled animals. In Europe, a quota system was in place until April 2015 to limit the amount of milk produced annually per country, but also per farmer (Bergevoet et al., 2004). Individual farmers that produced more than the allowed quota had to pay a penalty for the excess of milk they produced. This system might have affected culling reasons over the years. From 1990 to 2014 the average herd size increased, milk production per cow increased, and fertility declined in the Netherlands (CRV, 2015). Also, worldwide, national selection indexes have changed drastically over the past 2 decades, where the breeding goal moved from selection for production only toward selection for production, longevity, and health traits (Miglior et al., 2005). This might have changed the perception of the right culling reasons for dairy farmers. Currently, in the genetic evaluation in the Netherlands, $30 \mathrm{yr}$ of records are included, but it is still assumed to be 1 trait.

In the Netherlands, farmers can voluntarily record culling reasons, but not all farmers record these reasons and data are only available for the most recent years. Recorded culling reasons are subjective scores of the farmer, and culling of a cow is often done for multiple reasons (Fetrow et al., 2006). For example, poor fertility or bad udder health combined with a low daily milk yield will result in a cow not being inseminated again. For these reasons, it is difficult to evaluate if culling reasons have changed over the years. Another way to 
evaluate changes in the trait survival is to analyze phenotypic records for longevity and compare the mean and standard deviation across years; however, this provides little information if the trait definition (i.e., culling reasons) of survival changed. The trait definition can be also evaluated by analyzing if daughters of the same bulls survive longest in each year or if a reranking of bulls occurred. Genetic links between animals culled in different years allow estimation of genetic correlations between years, and a unity correlation is expected when culling reasons are not different between years. In the United States, changes in productive life were analyzed over a 15-yr period (Tsuruta et al., 2004), and in Australia survival of first lactation was analyzed over a 20-yr period (Haile-Mariam and Pryce, 2015). In both studies multitrait and random regression models were used to detect changes in their survival trait, and in both studies it appeared that with random regression models genetic correlations between survival in different years were high. However, with multitrait models, estimated genetic correlations were as low as 0.21 , with large standard errors (Haile-Mariam and Pryce, 2015), and 0.22 (Tsuruta et al., 2004); therefore, it was difficult to conclude if survival in the United States and Australia changed in those years.

Two different definitions for survival were proposed by Ducrocq (1987): survival and functional survival. Survival is defined as the ability to delay culling, and functional survival is defined as the ability to delay involuntary culling. Adjustment of survival for individual deviation from within-herd production levels provides an approximation of functional survival. By adjusting for production level, the assumption is made that functional survival is independent of voluntary culling, assuming that voluntary culling is primarily for low production. Voluntary culling is an economic decision of the farmer because more profit from a new heifer is expected. If involuntary culling is decreased, a higher voluntary culling rate can be applied, resulting in a larger profit for the farmer, but not necessarily increasing longevity as a whole (Van Arendonk, 1985). It is of interest to investigate whether survival and functional survival have evolved differently over time.

The objective of this study was to evaluate if survival in first lactation has become a different trait over the past $25 \mathrm{yr}$ or not, and if this is affected by adjusting for production level or not. This was achieved by computing the genetic correlation between survival of first parities starting in different years. For the Dutch situation, it was the first time that such a long time span could be analyzed, as data on survival has been available in the Netherlands since 1988.

\section{MATERIALS AND METHODS}

\section{Data}

In this study, 2 definitions for survival after first calving were used: (1) survival until mo 12 (surv_12mo; i.e., the animal did not die or was not culled for slaughter), and (2) survival of first lactation (surv_1st_lac; i.e., a cow was considered to have survived first lactation if she had initiated her second lactation). Besides surv_12mo, we analyzed surv_1st_lac because over the past decades calving interval has increased and culling for infertility could have shifted beyond mo 12. Survival in early life was analyzed instead of total lifespan, because information for surv_12mo and surv_1st_lac is more rapidly available for each animal compared with lifespan, and, more importantly, because the modeling of the data is less complex. With only first-lactation animals, all animals within a calving year can be directly compared instead of comparing a mixture of different age groups at the same time within a herd.

The surv_12mo and surv_1st_lac were coded as 1 for animals that survived and as 0 for animals that died or were culled for slaughter. Data were available from the Dutch and Flemish cattle improvement cooperative CRV, and cows with first calving between 1989 and 2013 were used. Records for survival were constructed from records of pedigree, lactations, and movements of cows in the Netherlands. All animals were a combination of at least $87.5 \%$ Holstein Friesian and Dutch Friesian, and the required age at first calving was between 21 and 40 mo. Herds with at least 95\% Holstein Friesian and Dutch Friesian genes were selected. Only herds with at least 30 cows present every month, in the period from 1994 to 2013, were selected to exclude herds with a nonconventional culling management; for example, because the farm has stopped or the entire herd was culled at once because of the outbreak of a disease. Additional requirements were that sires had at least 15 progeny or grand-progeny that could have been productive for at least $12 \mathrm{mo}$ after first calving, sires had progeny in at least 2 herds, and every herd-year-month class had at least 25 observations. The additional requirements for progeny per sire, herds per sire, and observations per herd-year-month had to be repeated 11 times until the final data set met all criteria. The creation of the final data set with surv_12mo and surv_1st_lac was as follows. For surv_12mo, animals were selected that could have been in the herd for at least 12 mo after first calving (i.e., animals calving after 31 December 2013 were excluded); the data set with surv_12mo contained 1,108,745 animals. For surv_1st_lac, animals were se- 
lected that could have been in the herd for at least 18 mo after first calving (i.e., animals calving after 30 June 2013 were excluded); the data set with surv_1st_lac contained 1,062,276 animals. In both data sets 2,185 herds were included. Pedigree information of the sires and maternal grandsires was traced back 6 generations, resulting in a pedigree file with 11,268 sires.

\section{Statistical Model}

To determine whether genetic parameters for survival changed across years, the period of $25 \mathrm{yr}$ was split into 5 intervals of 5 yr (1989-1993, 1994-1998, 1999-2003, 2004-2008, and 2009-2013) and analyzed as 5 traits. The basic mixed model equation for all models to analyze survival was:

$$
\mathbf{y}=\mathbf{X b}+\left(\mathbf{Z}_{\mathrm{s}}+\mathbf{Z}_{\mathrm{mgs}} / 2\right) \mathbf{u}_{\mathrm{s}}+\mathbf{e},
$$

where $\mathbf{y}$ is a vector of observations $(0 / 1)$ for survival (surv_12mo or surv_1st_lac); $\mathbf{X}$ is an incidence matrix linking the observations to the fixed effects; $\mathbf{b}$ is a vector of fixed effects of herd-year of first calving, year-month of first calving, fixed regression on age at first calving ( 15 classes: $21,22, \ldots, 34, \geq 35 \mathrm{mo}$ ) with a second-order Legendre polynomial, and percentage of Holstein Friesian genes, divided into 5 classes $(\leq 50.0$, $62.5,75.0,87.5$, and $100 \%) ; \mathbf{Z}_{\mathrm{s}}$ and $\mathbf{Z}_{\mathrm{mgs}}$ are the incidence matrices for sire and maternal grandsire, which are overlaid to estimate random sire effects; $\mathbf{u}_{\mathbf{s}}$ is the vector of random sire effects; and $\mathbf{e}$ is a vector of random residual effects. The variances were defined as

$$
\operatorname{Var}\left[\begin{array}{l}
\mathbf{u} \\
\mathbf{e}
\end{array}\right]=\left[\begin{array}{cc}
\mathbf{G} \otimes \mathbf{A} & 0 \\
0 & \mathbf{R} \otimes \mathbf{I}
\end{array}\right],
$$

where $\mathbf{G}$ is the $5 \times 5$ sire (co)variance matrix for five 5 -yr intervals; $\mathbf{A}$ is the additive genetic relationship matrix between sires; $\mathbf{R}$ is a $5 \times 5$ diagonal heterogeneous residual (co)variance matrix for five 5 -yr intervals; $\mathbf{I}$ is identity matrix; and $\otimes$ is the Kronecker product.

\section{Bivariate Analysis}

We first used a bivariate model to estimate genetic correlations between all pairwise combinations of 5-yr intervals. To validate the consistency of the genetic correlations for survival, 2 alternative models were considered. The first alternative model was surv_12mo analyzed as functional survival, where survival was adjusted for individual production level relative to the production level of the herd; this has been suggested as a way to correct for voluntary culling due to low production (Robertson, 1966). Therefore, for functional survival, a fixed effect for within-herd production level was included, where within-herd production level was the cow ranking within a herd by 5 -yr interval for predicted or realized 305-d yield of combined kilograms of fat and protein. Animals were ranked into 7 classes from worst to best for combined kilograms of fat and protein, as (1) 1 to $5 \%$, , (2) 6 to $20 \%$, (3) 21 to $40 \%$, , (4) 41 to $60 \%$, (5) 61 to $80 \%$, (6) 81 to $95 \%$, and (7) 96 to $100 \%$. The second alternative model was surv_12mo analyzed with a threshold model, using the logit link function, to test for a difference in estimated parameters of linear and threshold models with high survival rates.

Our base model was the linear model for surv_12mo because our interest was if surv_12mo changed genetically over $25 \mathrm{yr}$. In subsequent analyses we changed the base model to explore sensitivity of the assumptions. In analysis 2 we changed the trait from surv_12mo to surv_1st_lac to analyze the effect of culling in late lactation on the genetic correlations between intervals; in analysis 3 we added the fixed effect for within-herd production level to analyze functional surv_12mo; and in analyses 4 and 5 we used a threshold model instead of a linear model to validate that ranking of bulls was similar to a linear model for surv_12mo and functional surv_12mo, respectively.

Variance components were estimated with ASReml (Gilmour et al., 2015). Heritability for each 5-yr interval was calculated as $4 \times$ sire variance divided by the sum of $1.25 \times$ sire variance $(1$ for the sire and 0.25 for the maternal grandsire) plus the residual variance of the corresponding interval.

\section{Alternative Parameterizations}

For some combinations of 5-yr intervals the number of common sires and maternal grandsires was very low (Table 1), indicating poor genetic links. Because of the poor connectedness between the extreme 5-yr intervals, we also examined more parsimonious models to estimate the genetic (co)variance matrix $\mathbf{G}$ on the full data set. The following models were used [examples of genetic (co)variance matrix $\mathbf{G}$ are displayed for the multivariate and autoregressive models in Figure 1].

(a) Univariate model with one genetic effect and homogeneous residual variances for 5-yr intervals $\left(\mathrm{UN}_{\text {hom }}\right)$.

(b) Univariate model with one genetic effect and heterogeneous residual variances for 5 -yr intervals $\left(\mathrm{UN}_{\text {het }}\right)$.

(c) Uncorrelated multivariate model with heterogeneous variances $\left(\mathrm{MT}_{\mathrm{UC}}\right)$, which is equivalent 


$$
\begin{aligned}
& {\left[\begin{array}{lllll}
1 & 0 & 0 & 0 & 0 \\
0 & 1 & 0 & 0 & 0 \\
0 & 0 & 1 & 0 & 0 \\
0 & 0 & 0 & 1 & 0 \\
0 & 0 & 0 & 0 & 1
\end{array}\right]\left[\begin{array}{lllll}
1 & a & a & a & a \\
a & 1 & a & a & a \\
a & a & 1 & a & a \\
a & a & a & 1 & a \\
a & a & a & a & 1
\end{array}\right]\left[\begin{array}{lllll}
1 & a & b & d & g \\
a & 1 & c & e & h \\
b & c & 1 & f & i \\
d & e & f & 1 & j \\
g & h & i & j & 1
\end{array}\right]\left[\begin{array}{lllll}
1 & a & b & c & d \\
a & 1 & a & b & c \\
b & a & 1 & a & b \\
c & b & a & 1 & a \\
d & c & b & a & 1
\end{array}\right]} \\
& \begin{array}{llll}
\text { MT }_{U C} & \text { MT }_{0.95} \text { and } \mathrm{MT}_{0.99} & \text { MT }_{\text {US }} & \text { AR1, AR1 } \\
0.90 & \text { and AR2 }
\end{array}
\end{aligned}
$$

Figure 1. Genetic covariance structures fitted to full data set for survival for the multitrait (MT) and autoregressive (AR) models. Different letters ( $a, b$, and so on) represent different values of correlation. $\mathrm{MT}_{\mathrm{UC}}$ has an uncorrelated covariance (UC) matrix; $\mathrm{MT}_{0.95}$ and $\mathrm{MT}_{0.99}$ have constrained correlations, where $a$ is 0.95 and 0.99 . $\mathrm{MT}_{\mathrm{US}}$ has an unstructured (US) covariance matrix. First-order autoregressive (AR1) correlation $C_{i i}=1, C_{i+1, \mathrm{i}}=\phi_{1}$, and $C_{i j}=\phi_{1} C_{i-j}$. In AR $1_{0.90}$ parameter $\phi_{1}$ is constrained to 0.90. Second-order autoregressive (AR2) correlation $C_{i i}=$ $1, C_{i+1, i}=\phi_{1} /\left(1-\phi_{2}\right)$, and $C_{i j}=\phi_{1} C_{i-1, j}+\phi_{2} C_{i-2, j}$. For AR1, AR $1_{0.90}$, and AR2, $a$ is $C_{i+1, i}$ and $b, c$, and $d$ are $C_{i j}$.

to a separate univariate analysis for each 5-yr interval. All covariances in $\mathbf{G}$ are zero.

(d) Multivariate model with a constrained correlation of 0.95 between all 5-yr intervals and with heterogeneous variances for 5 -yr intervals $\left(\mathrm{MT}_{0.95}\right)$.

(e) Multivariate model with a constrained correlation of 0.99 between all 5-yr intervals and with heterogeneous variances for 5 -yr intervals $\left(\mathrm{MT}_{0.99}\right)$.

(f) Full multivariate model with heterogeneous variances for 5-yr intervals, where the additive genetic (co)variance matrix $\mathbf{G}$ is an unstructured matrix $\left(\mathbf{M} \mathbf{T}_{\mathbf{U S}}\right)$.

(g) First-order autoregressive (AR) model with heterogeneous variances for 5-yr intervals (AR1). Matrix G has an autoregressive correlation structure with the correlation function $C_{i i}=1$, $C_{i+1, i}=\phi_{1}$, and $C_{i j}=\phi_{1} C_{i-1, j}$. Only one extra parameter, $\phi_{1}$, is needed, besides the variances, to estimate the genetic correlation structure.

(h) First-order autoregressive model with heterogeneous variances for 5 -yr intervals and constrained parameter $\phi_{1}$ of $0.90\left(\mathbf{A R} \mathbf{1}_{\mathbf{0 . 9 0}}\right)$. (i) Second-order autoregressive model with heterogeneous variances for 5-yr intervals (AR2). Matrix $\mathbf{G}$ has an autoregressive correlation structure with the correlation function where correlation $C_{i i}=1, C_{i+1, i}=\phi_{1} /\left(1-\phi_{2}\right)$, and $C_{i j}=\phi_{1} C_{i-1, j}+\phi_{2} C_{i-2, j}$. Two extra parameters, $\phi_{1}$ and $\phi_{2}$, are needed, besides the variances, to estimate the genetic correlation structure.

\section{Model Comparison}

For selection of the best-fit model among the 9 alternative models, Akaike's information criteria (AIC), and Bayesian information criteria (BIC) were used. The AIC and BIC were defined as:

$$
\begin{aligned}
& \mathrm{AIC}=2 \log \left(L_{i}\right)+2 t_{i}, \text { and } \\
& \mathrm{BIC}=-2 \log \left(L_{i}\right)+t_{i} \log v,
\end{aligned}
$$

where $L_{i}$ is the log-likelihood of model $i, t_{i}$ is the number of (co)variance parameters to estimate in model $i$ and $v=n-p$ is the residual degrees of freedom, where $n$ was the number of observations and $p$ was the

Table 1. Number of common sires and maternal grandsires (in parentheses) in same 5-yr interval (diagonal) and in two 5-yr intervals (below diagonal)

\begin{tabular}{lccccc}
\hline Item & $1989-1993$ & $1994-1998$ & $1999-2003$ & $2004-2008$ & $2009-2013$ \\
\hline $1989-1993$ & 2,195 & & & & \\
$1994-1998$ & $(1,988)$ & & & \\
& 697 & 2,557 & & \\
$1999-2003$ & $(1,855)$ & $(3,679)$ & & & \\
& 179 & 759 & 3,186 & & \\
$2004-2008$ & $(737)$ & $(2,463)$ & $(4,649)$ & 3,189 & \\
& 90 & 259 & 1,029 & $(5,239)$ & 2,569 \\
$2009-2013$ & $(168)$ & $(894)$ & $(2,992)$ & 1,125 & $(5,281)$ \\
& 43 & 130 & 349 & $(3,336)$ & \\
\hline
\end{tabular}


number of estimable fixed effects in the model. The AIC (Akaike, 1973) and BIC (Schwarz, 1978) were calculated for each model and the model with the smallest value was considered the preferred model. In addition, when AIC and BIC gave a different preferred model, the ranking based on $\mathrm{AIC}$ and $\mathrm{BIC}$ were combined and the model with the best overall ranking was considered the preferred model.

\section{RESULTS}

Mean survival rate was $87.8 \%$ for surv_ 12 mo and $83.2 \%$ for surv_1st_lac in the total data set. Between 1989 to 1993 and 2009 to 2013 survival increased by $7.3 \%$ for surv_12mo and $7.1 \%$ for surv_1st_lac (Table 2 ). The largest increase in mean survival rate was between 1994 to 1998 and 2004 to 2008 for both surv_12mo (5.4\%) and surv_1st_lac (5.7\%). Mean survival rates were more similar for 5-yr intervals 1989 to 1993 and 1994 to 1998, as well as for intervals 2004 to 2008 and 2009 to 2013. The difference between surv_12mo and surv_1st_lac can be considered as culling at the end of lactation, and their difference varied between 4 and 5\% across all 5-yr intervals. However, the relative reduction of percentage culled animals from 1989 to 1993 and 2009 to 2013 was $44 \%$ for surv_ 12 mo and $35 \%$ for surv_1st_lac. Therefore, in more recent years, animals are more likely culled after 12 mo.

\section{Variances and Heritabilities}

Parameter estimates for survival across 5-yr intervals based on bivariate analyses are shown in Tables 3, 4, 5, 6, and 7. Across 5-yr intervals genetic and residual standard deviations reduced for all 4 analyses. The decrease of genetic standard deviations was relatively larger for surv_12mo (Table 3) and surv_1st_lac (Table 4) than for functional surv_12mo (Table 5). Residual standard deviations also decreased across 5 -yr intervals, except for surv_12mo and functional surv_12mo analyzed with the threshold model, which has by definition equal residual variances for both traits (Table 6 and 7). The changes in genetic and residual standard deviations were not proportional; the relative decrease of residual standard deviations was smaller compared with the relative decrease of the genetic variance. This resulted in decreasing heritabilities across 5-yr intervals. When surv_12mo was adjusted for within-herd production level, this is functional survival, heritability for the first three 5-yr intervals was constant, followed by lower heritabilities in the later 5 -yr intervals (Table 5). Heritabilities of survival across 5 -yr intervals estimated with the threshold model were decreasing as well, similar to the linear models (Table 6), where heritabilities for functional survival were more constant again (Table 7). When heritabilities estimated with a linear model for surv_12mo were transformed to the underlying scale with the formula of Dempster and Lerner (1950), they were similar to the heritabilities from the threshold model (0.04-0.14). Heritabilities on the underlying scale for functional surv_12mo ranged from 0.07 to 0.10 and for surv_1st_lac from 0.06 to 0.12 .

\section{Genetic Correlations}

Most genetic correlations obtained with the bivariate analyses were higher than 0.85 and did not differ significantly from unity. The few genetic correlations that did differ significantly from unity were high $(>0.80)$. Standard errors of the genetic correlations became larger when two 5-yr intervals were further apart, because the number of sires and maternal grandsires with progeny in both intervals decreased when intervals were further apart (Table 1). Pooled over 10 bivariate analyses per model, the average correlation between 5-yr intervals was 0.91 for surv_12mo, 0.87 for surv_1st_lac, and 0.87 for surv_12mo with the threshold model. Adjusting for within-herd production level resulted in a higher average correlation of 0.93 for functional surv_12mo and 0.91 for functional surv_12mo with the threshold model. Also, the range of genetic correlations was smaller for functional surv_12mo $(0.86-1.00)$ than for surv_12mo (0.74-0.99). However, based on standard errors of the genetic correlations, it was difficult to conclude whether difference existed between the models or whether survival between 5-yr intervals differed genetically (i.e., genetic correlations below unity).

\section{Alternative Parameterizations of Genetic Covariances}

Table 8 contains the results of the comparison of alternative parameterizations of the genetic covariance structure G. In comparison with the bivariate analyses, all 5-yr intervals were included rather than two 5 -year intervals at the time; most parameterizations of $\mathbf{G}$ converged, except $\mathrm{MT}_{\mathrm{US}}$. This exception was the

Table 2. Number of cows and mean survival rate (\%) for survival after first calving and survival of first lactation per 5-yr interval

\begin{tabular}{lccccc}
\hline & \multicolumn{2}{c}{ Survival at 12 mo } & & \multicolumn{2}{c}{ Survival of first lactation } \\
\cline { 2 - 3 } \cline { 6 - 6 } 5-yr interval & No. of cows & Mean & & No. of cows & Mean \\
\hline $1989-1993$ & 175,822 & 83.4 & & 174,216 & 79.5 \\
$1994-1998$ & 209,941 & 84.9 & & 207,547 & 80.1 \\
$1999-2003$ & 226,278 & 88.0 & & 222,360 & 83.0 \\
$2004-2008$ & 236,362 & 90.3 & & 231,588 & 85.8 \\
$2009-2013$ & 260,342 & 90.7 & & 226,565 & 86.6 \\
\hline
\end{tabular}


Table 3. Genetic standard deviation $\left(\sigma_{A}\right)$, residual standard deviation $\left(\sigma_{E}\right)$, heritability (in bold on the diagonal), and genetic correlations (offdiagonal) for survival at 12 mo after first calving divided in five 5-yr intervals (SE in parentheses)

\begin{tabular}{|c|c|c|c|c|c|c|c|}
\hline \multirow[b]{2}{*}{ 5-yr interval } & \multirow[b]{2}{*}{$\sigma_{A}$} & \multirow[b]{2}{*}{$\sigma_{E}$} & \multicolumn{5}{|c|}{ Heritability and genetic correlations } \\
\hline & & & 1989-1993 & 1994-1998 & $1999-2003$ & $2004-2008$ & 2009-2013 \\
\hline 1994-1998 & 0.084 & 0.353 & $0.88(0.04)$ & $0.056(0.006)$ & & & \\
\hline 1999-2003 & 0.059 & 0.320 & $0.95(0.06)$ & $0.98(0.02)$ & $0.034(0.006)$ & & \\
\hline $2004-2008$ & 0.044 & 0.293 & $0.74(0.19)$ & $0.83(0.08)$ & $0.96(0.03)$ & $0.022(0.006)$ & \\
\hline 2009-2013 & 0.033 & 0.288 & $0.97(0.22)$ & $0.99(0.09)$ & $0.86(0.09)$ & $0.90(0.05)$ & $0.013(0.006)$ \\
\hline
\end{tabular}

Table 4. Genetic standard deviation $\left(\sigma_{A}\right)$, residual standard deviation $\left(\sigma_{E}\right)$, heritability (in bold on the diagonal), and genetic correlations (offdiagonal) for survival of first lactation divided in five 5-yr intervals (SE in parentheses)

\begin{tabular}{|c|c|c|c|c|c|c|c|}
\hline \multirow[b]{2}{*}{ 5-yr interval } & \multirow[b]{2}{*}{$\sigma_{A}$} & \multirow[b]{2}{*}{$\sigma_{E}$} & \multicolumn{5}{|c|}{ Heritability and genetic correlations } \\
\hline & & & 1989-1993 & 1994-1998 & $1999-2003$ & $2004-2008$ & 2009-2013 \\
\hline 1994-1998 & 0.091 & 0.393 & $0.84(0.05)$ & $0.053(0.006)$ & & & \\
\hline 1999-2003 & 0.078 & 0.370 & $0.94(0.06)$ & $0.92(0.03)$ & $0.044(0.006)$ & & \\
\hline 2004-2008 & 0.066 & 0.344 & $0.76(0.17)$ & $0.80(0.08)$ & $0.94(0.03)$ & $0.036(0.006)$ & \\
\hline 2009-2013 & 0.051 & 0.337 & $0.80(0.31)$ & $0.91(0.12)$ & $0.87(0.07)$ & $0.95(0.03)$ & $0.023(0.005)$ \\
\hline
\end{tabular}

Table 5. Genetic standard deviation $\left(\sigma_{A}\right)$, residual standard deviation $\left(\sigma_{E}\right)$, heritability (in bold on the diagonal), and genetic correlations (offdiagonal) for functional survival at $12 \mathrm{mo}$ after first calving divided in five 5 -yr intervals (SE in parentheses)

\begin{tabular}{|c|c|c|c|c|c|c|c|}
\hline \multirow[b]{2}{*}{5 -yr interval } & \multirow[b]{2}{*}{$\sigma_{A}$} & \multirow[b]{2}{*}{$\sigma_{E}$} & \multicolumn{5}{|c|}{ Heritability and genetic correlations } \\
\hline & & & 1989-1993 & $1994-1998$ & 1999-2003 & $2004-2008$ & 2009-2013 \\
\hline 1994-1998 & 0.068 & 0.336 & $0.92(0.04)$ & $0.040(0.005)$ & & & \\
\hline 1999-2003 & 0.062 & 0.308 & $0.93(0.07)$ & $1.00(0.01)$ & $0.039(0.005)$ & & \\
\hline 2004-2008 & 0.048 & 0.284 & $0.96(0.12)$ & $0.91(0.06)$ & $1.00(0.01)$ & $0.028(0.005)$ & \\
\hline 2009-2013 & 0.043 & 0.279 & $0.90(0.18)$ & $0.86(0.13)$ & $0.90(0.06)$ & $0.94(0.03)$ & $0.023(0.005)$ \\
\hline
\end{tabular}

Table 6. Genetic standard deviation $\left(\sigma_{A}\right)$, residual standard deviation $\left(\sigma_{E}\right)$, heritability (in bold on the diagonal), and genetic correlations (offdiagonal) for survival at 12 mo after first calving divided in five 5-yr intervals (SE in parentheses) estimated with a threshold model

\begin{tabular}{|c|c|c|c|c|c|c|c|}
\hline 5 -yr interval & $\sigma_{A}$ & $\sigma_{E}$ & \multicolumn{5}{|c|}{ Heritability and genetic correlations } \\
\hline $1989-1993$ & 0.721 & 1.814 & $0.150(0.015)$ & & & & \\
\hline 1999-2003 & 0.566 & 1.814 & $0.93(0.07)$ & $0.97(0.02)$ & $0.095(0.013)$ & & \\
\hline 2004-2008 & 0.500 & 1.814 & $0.69(0.19)$ & $0.80(0.09)$ & $0.94(0.04)$ & $0.075(0.013)$ & \\
\hline 2009-2013 & 0.412 & 1.814 & $0.83(0.27)$ & $0.98(0.11)$ & $0.84(0.09)$ & $0.89(0.05)$ & $0.052(0.012)$ \\
\hline
\end{tabular}

Table 7. Genetic standard deviation $\left(\sigma_{A}\right)$, residual standard deviation $\left(\sigma_{E}\right)$, heritability (in bold on the diagonal), and genetic correlations (offdiagonal) for functional survival at 12 mo after first calving divided in five 5 -yr intervals (SE in parentheses) estimated with a threshold model

Heritability and genetic correlations

\begin{tabular}{|c|c|c|c|c|c|c|c|}
\hline \multirow[b]{2}{*}{5 -yr interval } & \multirow[b]{2}{*}{$\sigma_{A}$} & \multirow[b]{2}{*}{$\sigma_{E}$} & \\
\hline & & & 1989-1993 & 1994-1998 & 1999-2003 & 2004-2008 & 2009-2013 \\
\hline $1994-1998$ & 0.600 & 1.814 & $0.89(0.05)$ & $0.106(0.013)$ & & & \\
\hline 2009-2013 & 0.539 & 1.814 & $0.90(0.19)$ & $0.83(0.14)$ & $0.89(0.07)$ & $0.90(0.04)$ & $0.086(0.012)$ \\
\hline
\end{tabular}


main reason why the results of the bivariate analyses were presented above. The parsimonious models gave similar heritability estimates, except for the univariate models. According to the AIC, AR1 was the best model for surv_12mo and functional surv_12mo, and $\mathrm{AR} 1_{0.90}$ was the best model for surv_1st_lac. According to the BIC, which puts a higher penalty when modeling more variance components, $\mathrm{AR} 1_{0.90}$ was the best model for surv_12mo and surv_1st_lac and $\mathrm{MT}_{0.95}$ was the best model for functional surv_12mo. Ranking models according to both AIC and BIC suggests that, for surv_12mo and surv_1st_lac, AR1, AR $1_{0.90}$, and $\mathrm{MT}_{0.95}$ gave a better fit than the other parameterizations, and for functional survival $\mathrm{MT}_{0.95}, \mathrm{AR} 1$, and multivariate model with a correlation of 0.99 gave a better fit.

With AR1 the estimated autoregressive correlations $\phi_{1}$ were 0.94 for surv_12mo, 0.92 for surv_1st_lac, 0.93 for surv_12mo estimated with the threshold model, 0.97 for functional surv_12mo, and 0.96 for functional surv_12mo estimated with the threshold model; this resulted in genetic correlations between the most extreme intervals of $0.78,0.73,0.74,0.88$, and 0.83 respectively (Table 9). Compared with the bivariate analyses, standard errors of the genetic correlations were smaller because the full data set was used (all 5-yr intervals simultaneously), resulting in better connectedness due to common sires and a more parsimonious model with fewer variance components. Interestingly, for functional surv_12mo, genetic correlations were closer to unity compared with the analyses without adjusting for within-herd production level. This was supported by the model comparison which suggest that models with a fixed genetic correlations of 0.95 and 0.99 were better for functional survival. The average genetic correlations from the bivariate model between two 5-yr intervals with zero, one, or two 5-yr intervals in between, were in agreement with the estimates from the autoregressive model (Table 9). Both the bivariate analyses and the autoregressive models showed genetic correlations for survival between 5-yr intervals closer to unity for functional survival than for survival. Therefore, when adjusting for within-herd production level, we found little change in the survival trait over the past $25 \mathrm{yr}$.

\section{DISCUSSION}

In the current study, we investigated the changes in survival over the past $25 \mathrm{yr}$ in the Netherlands and used genetic parameters to evaluate whether survival was a different trait according to years of first calving. Raw means for survival of first lactation increased from 79.5 to $86.6 \%$ over the past $25 \mathrm{yr}$, whereas in Australia survival of first lactation appeared to be stable around 85\% between 1993 and 2010 (Haile-Mariam and Pryce, 2015); in the United States, between 1980 and 2000, survival of first lactation decreased from 77 to $72 \%$, followed by an increase to $74 \%$ (Hare et al., 2006). Although survival to 12 mo increased in our study, the difference between surv_12mo and surv_1st_lac was rather constant, with 4 to $5 \%$ between 1989 and 2013. The genetic correlation between surv_12mo and surv_1st_lac was 0.97 when survival of all 25 yr was analyzed as 1 trait. Because of this high genetic correlation, not all results for surv_1st_lac were shown. Of all culled first-parity cows, a larger proportion was culled after 12 mo in more recent years. In Germany, it was shown that culling at the end of first lactation is mainly due to infertility, up to $50 \%$ of all culling, whereas main

Table 8. Univariate (UN), multitrait (MT), and autoregressive models (AR) models fitted to the full data set for survival with the total number of variance components estimated (\#VC), the number of variance components estimated for the genetic (\#gen) and residual (\#res) components, the value to which the genetic correlations $\left(\mathrm{r}_{\mathrm{g}}=0,0.95,0.99\right)$ or the autoregressive parameter $\phi_{1}$ were constrained or estimated $(s$ was estimated from the data), Akaike's information criteria (AIC), and Bayesian information criteria (BIC) for each model for surv_12mo, surv_1st_lac, and functional surv_12mo ${ }^{1}$

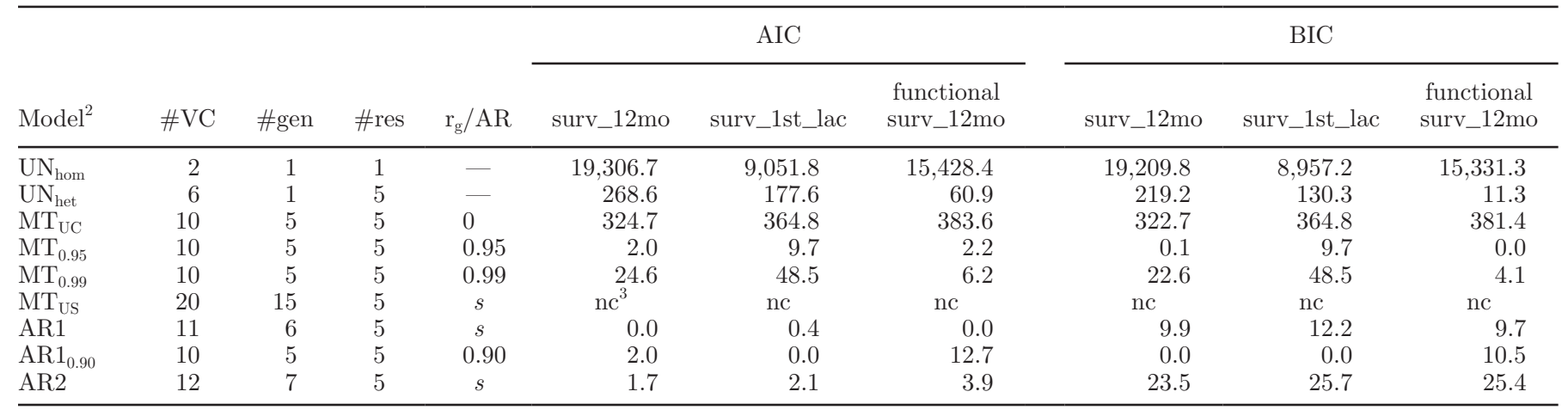

${ }^{1}$ Model with lowest AIC or BIC was set to 0.00. surv_12mo = survival until mo 12; surv_1st_lac = survival of first lactation.

${ }^{2}$ Descriptions of models can be found in the Alternative Parameterizations section.

${ }^{3} \mathrm{nc}=$ models that did not converge. 
Table 9. Genetic correlations between 5-yr intervals estimated with first-order autoregressive function and average genetic correlations from bivariate models for surv_12mo, surv_1st_lac, functional surv_12mo, and surv_12mo and functional surv_12mo estimated with a threshold model (SE in parentheses) ${ }^{1}$

\begin{tabular}{|c|c|c|c|c|c|}
\hline No. of 5 -yr intervals in between ${ }^{2}$ & surv_12mo & surv_1st_lac & $\begin{array}{l}\text { Functional } \\
\text { surv_12mo }\end{array}$ & $\begin{array}{l}\text { surv_12mo } \\
\text { (threshold) }\end{array}$ & $\begin{array}{c}\text { Functional surv_12mo } \\
\text { (threshold) }\end{array}$ \\
\hline \multicolumn{6}{|l|}{ Autoregressive } \\
\hline 2 & $0.83(0.04)$ & $0.79(0.04)$ & $0.91(0.03)$ & $0.80(0.04)$ & $0.87(0.04)$ \\
\hline 3 & $0.78(0.05)$ & $0.73(0.05)$ & $0.88(0.04)$ & $0.74(0.05)$ & $0.83(0.05)$ \\
\hline \multicolumn{6}{|l|}{ Bivariate } \\
\hline 2 & $0.87(0.14)$ & $0.84(0.14)$ & $0.91(0.12)$ & $0.83(0.15)$ & $0.87(0.14)$ \\
\hline 3 & $0.97(0.22)$ & $0.80(0.31)$ & $0.90(0.18)$ & $0.83(0.27)$ & $0.90(0.19)$ \\
\hline
\end{tabular}

${ }^{1}$ surv_12mo = survival until mo 12 ; surv_1st_lac = survival of first lactation.

${ }^{2}$ Combinations with 0 intervals between 5-yr intervals: 1989-1993 with 1994-1998, 1994-1998 with 1999-2003, 1999-2003 with 2004-2008, and 2004-2008 with 2009-2013; combinations with 1 interval between 5-yr intervals: 1989-1993 with 1999-2003, 1994-1998 with 2004-2008, and 1999-2003 with 2009-2013; combinations with 2 intervals between 5-yr intervals: 1989-1993 with 2004-2008, and 1994-1998 with 2009-2013; combinations with 2 intervals between 5-yr intervals: 1989-1993 with 2009-2013.

culling reasons until 12 mo were udder diseases, claw and leg disorders, metabolic diseases, and other diseases (Heise et al., 2016). In the United States, infertility was also one of the main culling reasons in first 3 lactations (Tsuruta et al., 2015). Thus, it is likely that relatively more emphasis has gone to culling for fertility in the past $25 \mathrm{yr}$, which agrees with the decline in fertility observed over the past decades (Veerkamp et al., 2015).

Genetic parameters for different 5-yr intervals were estimated using genetic links (i.e., sires and maternal grandsires) across existing data. Different covariance structures were modeled for the additive genetic effect to investigate whether survival changed genetically across years. Genetic correlations were analyzed with bivariate models using subsets of the full data set or with parsimonious models using the full data set. Bivariate analyses with subsets of the data many years apart proved of limited value to estimate the genetic correlations, as it was difficult to conclude if genetic correlations were different from unity. Although convergence was rather fast with these models, estimated genetic correlations had large standard errors (0.09-0.31). This was not surprising, because a small number of sires were common in 5 -yr intervals separated by 2 or more 5 -yr intervals. For example, only 1 sire had at least 10 daughters, and 3 sires had at least 10 granddaughters in both 5-yr intervals 1989 to 1993 and 2009 to 2013. To maintain genetic connectedness between the data collected over so many years, the full data set should always be considered and not split over time. A genomic relationship matrix could improve the connectedness between sires born in different years and separated by multiple generations, as was also observed when estimating genetic correlations between countries (Berry et al., 2014) or between traits (Veerkamp et al.,
2011), resulting in smaller standard errors. However, estimation of all the genetic correlations between all 5 -yr intervals might still be problematic given that genetic correlations are close to unity. Genetic correlations close to unity lead to estimation problems because sampling forces variance components to be outside the parameters space, but software packages try to estimate them within the parameter space. We attempted to estimate the full genetic (co)variance matrix allowing ASReml to get outside of the parameters space, but attempts were unsuccessful; therefore, we chose to analyze the full data set with parsimonious models. Parsimonious models that made a priori assumptions about the correlation structure for survival across the five 5 -yr intervals; the autoregressive models required only 1 (or 2) parameters to model the correlation structure, compared with $\mathrm{MT}_{\mathrm{US}}$ that used 10 covariances to describe the full genetic (co)variance matrix. The combined effect of being able to analyze data in all five 5 -yr intervals together and the simplified models was that standard errors became smaller and convergence improved. Analyses of $\mathrm{MT}_{\mathrm{US}}$ resulted in convergence problems and nonpositive definitive matrices. Many other parsimonious models could be used. Another parsimonious model that has been used is for estimating the genetic correlation for survival across many years is the random regression model (Tsuruta et al., 2004; Haile-Mariam and Pryce, 2015). A random regression model is more often applied to estimate genetic correlation over a time trajectory on the same animal [i.e., lactation curve Schaeffer and Dekkers, 1994), weight (Meyer, 2004), or survival (Veerkamp et al., 2001; van Pelt et al., 2015)], but can also be used to model traits in different animals in different environments (Calus and Veerkamp, 2003). A random regression model ap- 
pears also very well suited to model longevity over a time span of 25 yr. However, more general solutions exist to fit parsimonious models to a set of highly correlated traits (Thompson et al., 2003, 2005); these have not been attempted here, as we expect little difference from the autoregressive models.

We saw that genetic variance, residual variance, phenotypic variance, and heritability decreased over $25 \mathrm{yr}$. Because the mean survival rate, $p$, increased, a reduction of phenotypic variance, which is $p(1-p)$, was expected. With an increase in survival rate it was expected that the heritability on the observed scale would decrease with the linear model when the heritability on the underlying scale was constant. However, heritability estimates from the threshold model also decreased across 5-yr intervals, albeit less for functional survival. Across all analyses, heritability in 1989 to 1993 was 2 to 5 times higher than heritability in 2009 to 2013. This continuous reduction in heritability was not found in other studies analyzing survival of first lactation (Haile-Mariam and Pryce, 2015) or productive life (Tsuruta et al., 2004). A difference with those studies was that survival of first lactation or productive life did not improve over time. Though the effects of selection are relatively slow, we considered it important to evaluate the change in genetic parameters over a longer time period; the data from the current study are also included in the genetic evaluation for longevity.

Ducrocq (1987) proposed 2 different trait definitions for survival: survival and functional survival. Survival is defined as the ability to delay culling and functional survival is defined as the ability to delay involuntary culling only. According to this definition, functional survival rather than survival is the trait that should be selected for, and it is the genetic correlation between functional survival and milk yield which is of primary interest for dairy cattle breeders (Essl, 1998). Adjustment of survival for within-herd production level provides an approximation of functional survival, and most countries participating in the Interbull evaluation for longevity (14 out of 19) accounted for production in their national evaluation for survival (Forabosco et al., 2009). In the Netherlands, a genetic evaluation for functional longevity was introduced in 1999, but changed to longevity in 2008. The effect of adjusting for within-herd milk production is shown in several results in the current study. For example, for functional survival heritability was stable $(\sim 0.04)$ between 1989 and 2004 (Table 5), whereas the heritability for survival decreased from 0.063 to 0.034 (Table 3).

Models assuming high genetic correlations between the years were significantly better for functional survival, whereas they were not for survival. More convincingly, genetic correlations between the 5 -yr intervals were with all models (bivariate models using subsets of the full data set, with parsimonious models using the full data set, or linear models or threshold models) lower for survival than for functional survival. For functional survival, most genetic correlations between different 5 -yr intervals were $\geq 0.90$, indicating that when adjusting for within-herd milk production survival did not change across the 25 yr. For survival analyzed with a linear model for surv_12mo and surv_1st_lac or with a threshold model for surv_12mo, genetic correlations were $<0.90$ when 5 -yr intervals were separated by at least one 5-yr interval. Other studies found genetic correlations $<0.40$ for survival in 2 different periods that were separated by at least $10 \mathrm{yr}$ when using MT models (Tsuruta et al., 2004; Haile-Mariam and Pryce, 2015). Their standard errors of the genetic correlations were larger than in our study, and these low genetic correlations did not significantly differ from unity. Both studies used random regression fitting a Legendre polynomial of first order (intercept and linear) to estimate the genetic covariance structure. Haile-Mariam and Pryce (2015) found genetic correlations between different 2-yr intervals that were $>0.90$, and Tsuruta et al. (2004) found that most genetic correlations between breeding values for different years were $>0.70$. From these studies it was not obvious that survival changed across time, because results from different models were conflicting with each other. We concluded that the trait functional survival (i.e., involuntary culling) did not really change across years, and bulls rank more similar using functional survival in comparison with using survival. After adjusting for the deviation of individual production from herd production level, farmers were still culling animals for roughly the same reasons in, for example, 1995 and 2010. However, voluntary culling did change across years (Ducrocq, 1999), as shown by genetic parameters in our study, which agrees with phenotypic analyses performed on the same data set (van Pelt et al., 2016). van Pelt et al. (2016) showed that the effect of culling for within-herd production level changed in the past $25 \mathrm{yr}$, and in more recent years animals with low production had a lower risk of culling. Therefore, it is important that we consider adjusting for within-herd production level in the genetic evaluation to have more consistent breeding values, both for selection and for setting up the reference population for genomic prediction.

\section{CONCLUSIONS}

Analyses of 25 yr of data on survival in first lactation in Dutch dairy cattle demonstrated that survival increased, whereas genetic variances and heritability decreased. Genetic correlations between 5-yr intervals 
showed that survival changed over time, whereas genetic correlations for functional survival did not indicate that survival changed. The difference in genetic correlations between survival and functional survival are likely explained by less emphasis of dairy farmers on culling in first lactation for production in more recent years. This suggests that genetic evaluation for longevity using historical data should analyze functional survival rather than survival.

\section{ACKNOWLEDGMENTS}

The authors acknowledge funding from the Dutch Dairy Board (PZ; Zoetermeer, the Netherlands), Genetic Evaluation for Sires (GES) and cattle improvement cooperative CRV (Arnhem, the Netherlands) and the Breed4Food project (program "Kennisbasis Dier," code: BO-12-22.04-011-001-ASG-LR).

\section{REFERENCES}

Akaike, H. 1973. Information theory and an extension of the maximum likelihood principle. Pages 267-281 in Proc. 2nd Int. Symp. Information Theory. Akademiai Kiado, Budapest, Hungary.

Beaudeau, F., H. Seegers, V. Ducrocq, C. Fourichon, and N. Bareille. 2000. Effect of health disorders on culling in dairy cows: A review and a critical discussion. Ann. Zootech. 49:293-311.

Bergevoet, R. H. M., C. J. M. Ondersteijn, H. W. Saatkamp, C. M. J. van Woerkum, and R. B. M. Huirne. 2004. Entrepreneurial behaviour of Dutch dairy farmers under a milk quota system: Goals, objectives and attitudes. Agric. Syst. 80:1-21.

Berry, D. P., M. P. Coffey, J. E. Pryce, Y. de Haas, P. Lovendahl, N. Krattenmacher, J. J. Crowley, Z. Wang, D. Spurlock, K. Weigel, K. Macdonald, and R. F. Veerkamp. 2014. International genetic evaluations for feed intake in dairy cattle through the collation of data from multiple sources. J. Dairy Sci. 97:3894-3905.

Calus, M. P. L., and R. F. Veerkamp. 2003. Estimation of environmental sensitivity of genetic merit for milk production traits using a random regression model. J. Dairy Sci. 86:3756-3764.

CRV. 2015. CRV Jaarstatistieken Nederland 2015. CRV, Arnhem, the Netherlands.

Dempster, E. R., and M. Lerner. 1950. Heritability of threshold characters. Genetics 35:212-236.

Ducrocq, V. 1987. An analysis of length of productive life in dairy cattle. PhD thesis, Cornell University, Ithaca, NY.

Ducrocq, V. 1999. Two years of experience with the French genetic evaluation of dairy bulls on production-adjusted longevity of their daughters. Interbull Bull. 21:60-68.

Essl, A. 1998. Longevity in dairy cattle breeding: A review. Livest. Prod. Sci. 57:79-89.

Fetrow, J., K. V. Nordlund, and H. D. Norman. 2006. Invited review: Culling: Nomenclature, definitions, and recommendations. J. Dairy Sci. 89:1896-1905.

Forabosco, F., J. H. Jakobsen, and W. F. Fikse. 2009. International genetic evaluation for direct longevity in dairy bulls. J. Dairy Sci. 92:2338-2347.

Gilmour, A. R., B. Gogel, B. Cullis, S. Welham, and R. Thompson. 2015. ASReml User Guide Release 4.1 Functional Specification. VSN International Ltd., Hemel Hempstead, UK.
Haile-Mariam, M., and J. E. Pryce. 2015. Variances and correlations of milk production, fertility, longevity, and type traits over time in Australian Holstein cattle. J. Dairy Sci. 98:7364-7379.

Hare, E., H. D. Norman, and J. R. Wright. 2006. Survival rates and productive herd life of dairy cattle in the United States. J. Dairy Sci. 89:3713-3720.

Heise, J., Z. T. Liu, K. F. Stock, S. Rensing, F. Reinhardt, and H. Simianer. 2016. The genetic structure of longevity in dairy cows. J. Dairy Sci. 99:1253-1265.

LTO. 2011. Melkveehouderij: Midden in de maatschappij - Visie. LTO Nederland Vakgroep Melkveehouderij, Den Haag, the Netherlands.

Meyer, K. 2004. Scope for a random regression model in genetic evaluation of beef cattle for growth. Livest. Prod. Sci. 86:69-83.

Miglior, F., B. L. Muir, and B. J. Van Doormaal. 2005. Selection indices in Holstein cattle of various countries. J. Dairy Sci. 88:12551263.

Robertson, A. 1966. A mathematical model of culling process in dairy cattle. Anim. Prod. 8:95-108.

Schaeffer, L. R., and J. C. M. Dekkers. 1994. Random regressions in animal models for test-day production in dairy cattle. Pages 443-446 in Proc. Proc. 5th World Congr. Genet. Appl. Livest. Prod., Guelph, Ontario, Canada.

Schwarz, G. 1978. Estimating the dimension of a model. Ann. Stat. 6:461-464.

Thompson, R., S. Brotherstone, and I. M. S. White. 2005. Estimation of quantitative genetic parameters. Philos. Trans. R. Soc. Lond. B Biol. Sci. 360:1469-1477.

Thompson, R., B. Cullis, A. Smith, and A. Gilmour. 2003. A sparse implementation of the average information algorithm for factor analytic and reduced rank variance models. Aust. N. Z. J. Stat. 45:445-459.

Tsuruta, S., D. A. L. Lourenco, I. Misztal, and T. J. Lawlor. 2015. Genotype by environment interactions on culling rates and 305day milk yield of Holstein cows in 3 US regions. J. Dairy Sci. 98:5796-5805.

Tsuruta, S., I. Misztal, and T. J. Lawlor. 2004. Genetic correlations among production, body size, udder, and productive life traits over time in Holsteins. J. Dairy Sci. 87:1457-1468.

Van Arendonk, J. A. M. 1985. Studies on the replacement policies in dairy-cattle. 2. Optimum policy and influence of changes in production and prices. Livest. Prod. Sci. 13:101-121.

van Pelt, M. L., G. De Jong, and R. F. Veerkamp. 2016. Changes in the genetic level and the effects of age at first calving and milk production on survival during the first lactation over the last 25 years. Animal http://dx.doi.org/10.1017/S1751731116001282.

van Pelt, M. L., T. H. E. Meuwissen, G. De Jong, and R. F. Veerkamp. 2015. Genetic analysis of longevity in Dutch dairy cattle using random regression. J. Dairy Sci. 98:4117-4130.

Veerkamp, R. F., S. Brotherstone, B. Engel, and T. H. E. Meuwissen. 2001. Analysis of censored survival data using random regression models. Anim. Sci. 72:1-10.

Veerkamp, R. F., H. A. Mulder, R. Thompson, and M. P. L. Calus 2011. Genomic and pedigree-based genetic parameters for scarcely recorded traits when some animals are genotyped. J. Dairy Sci. 94:4189-4197.

Veerkamp, R. F., A. M. M. Tenghe, L. Kaal, and A. C. Bouwman. 2015. Genetics and genomics of fertility in dairy cows. Cattle Pract. 23:98-102.

Zijlstra, J., M. Boer, J. Buiting, K. Colombijn-Van der Wende, and E.-A. Andringa. 2013. Rapport 668: Routekaart Levensduur; Eindrapportage van het project "Verlenging levensduur melkvee". Wageningen UR Livestock Research, Wageningen, the Netherlands. 